\title{
When behaviour turns contagious: the use of deterministic epidemiological models in modeling social contagion phenomena
}

\author{
Joanna Sooknanan ${ }^{1}$ • Donna M. G. Comissiong ${ }^{2}$
}

Received: 15 September 2016 / Accepted: 17 September 2016 / Published online: 28 September 2016

(C) Springer-Verlag Berlin Heidelberg 2016

\begin{abstract}
Mathematical models offer crucial insights into the transmission dynamics and control of infectious diseases. These models have also been applied to investigate a variety of 'contagious' social phenomena like crime, opinions, addiction and fanaticism. We review the use and adaptation of models from epidemiology (compartmental models) to investigate the transmission dynamics of different social contagion processes- all of which are spread by contact only.
\end{abstract}

Keywords Compartmental models · Deterministic models · Epidemiology $\cdot$ Social phenomena $\cdot$ Addictions .

Social media $\cdot$ Crime

\section{Introduction}

Planking, the ice-bucket challenge, gossip and rumors . . . all familiar references but not with always the most pleasant of memories! Gladwell [1] recognised that some social phenomena like ideas and behavior are contagious. Social contagion refers to "the spread of affect or behaviour from one crowd participant to another; one person serves as the stimulus for the imitative actions of another" [2]. Words used to describe this phenomenon are reminiscent of terms used in epidemiology—contagion, infectiousness, spread, going viral etc.

\section{Donna M. G. Comissiong}

Donna.Comissiong@sta.uwi.edu

1 Centre for Education Programmes, The University of Trinidad and Tobago, West Indies, Trinidad

2 Department of Mathematics and Statistics, Faculty of Science and Technology, The University of the West Indies, St Augustine, Trinidad and Tobago
From a mathematical point of view, the spread of social contagion may be considered analogous to that of an infectious disease. This insight has led to the use and manipulation of models from epidemiology (compartmental models) to investigate the transmission dynamics of different contagion processes or 'traits' transmitted amongst individuals or groups. This 'trait' can refer to a disease, a genetic characteristic, a cultural characteristic, an addictive activity, or the gain or loss of information that is communicated through gossip or rumors [3]. The commonality in these 'traits' being that they are spread only by contact processes. A review of infectious disease models yielded three major categories of traits modeled which were 'compartmentalised' (aptly) into the following categories:

- S-Social addictions, eating disorders and the growth of church and political parties

- I-Information spread-traditional and modern

- R-Radical Behavior, fanaticism, crime and violence

Before we examine these models however, we review briefly the history and structure of compartmental models and give examples of their most recent use-the fight against the "emerging Zika pandemic" [4] which is of great concern to health officials and governments world-wide.

\section{A brief history of compartmental models}

Mathematical models offer crucial insights into the transmission dynamics and control of infectious diseases. Mathematical modelling has a long history in epidemiology. In terms of modern mathematical epidemiology, the first epidemic modeler was the physician Enko who between 1873 and 1894 formulated chain binomial models of disease spread. 
Modern mathematical epidemiology based on compartmental models, has its roots in the works of public health physicians Ross, Hamer, McKendrick and Kermack circa 1900-1935, who transformed theories of disease transmission into simplistic mathematical models [5,6]. In an analogy that has withstood the test of time, these models use ideas from chemical reaction kinetics to formulate a model of transmission that treats the interaction between susceptible and infected individuals as comparable to the collision of molecules.

Compartmental models divide a population of individuals into disjoint sub-groups or compartments based on infection status, age, social group, or other categories of interest or epidemiological relevance and attempt to describe the interactions between compartments. Here, only the state of an individual with respect to the disease is considered. The compartments are generally denoted by some or all of the letters SEIR where 'S' denotes Susceptible People (people who can catch the disease), 'E' denotes Exposed People (individuals who are infected but not yet infectious), 'I' denotes Infectious People (people who can transmit the disease), and 'R' denotes Recovered/ removed/immune people. This results in a system of nonlinear differential equations.

Permutations of these models have been used to describe infectious diseases like measles, rubella, chickenpox, smallpox, malaria, HIV/AIDS, bird flu and ebola. The robustness of these models are such that models for the "emerging Zika pandemic" [4] are being used to predict the transmission potential (as measured by the basic reproduction number $\mathrm{R}_{0}$ ), of the Zika virus infection [7], to model the transmission dynamics of Zika [8] and to recommend control strategies [9].

\section{Social contagion - the good, the bad and the ugly}

Most of the analytical models used in the social and behavioral sciences are linear models [10]. In nonlinear systems, proportionality does not hold: thus small changes can have dramatic and unanticipated effects-these are known as bifurcation points. The bifurcations give tipping points of the system where the system may make a sudden transition to a very different behavior. Linear models are favored by policy makers [11] since "they are mathematically tractable, easily fit to empirical data, and well understood by researchers" [10].

Human behaviour is inherently nonlinear [11], thus most of the social contagion processes to be modeled are inherently nonlinear. We now provide an overview of the different phenomena modeled by (nonlinear) compartmental models.

\section{Information spread (traditional and recent)}

In the early 1960s, Goffman and Newhill [12] compared the spread and growth of ideas by means of scientific literature to the spread of epidemics ('intellectual epidemics') using a SIR epidemic model and then applied this model to the history of mast cell research [13]. Here ' $S$ ' represents the size of the susceptible population, 'I' represents the size of the infected class (those who have adopted the new scientific idea, as manifested in their publications), and ' $\mathrm{R}(\mathrm{t})$ ' represents the size of the population who have recovered (no longer publishing on the topic). This SIR model was then extended by introducing a class ' $E$ ' of persons exposed to the intellectual infection and a class ' $\mathrm{Z}$ ' of skeptics [14]. It was also used to model the evolution in numbers of authors working in the field in six different emerging scientific fields [15]. Jin et al. [16] applied the SEIZ (susceptible, incubator, infected, and skeptic) model to news and rumors on Twitter.

The development and subsequent growth of the Internet has changed the way in which information is spread and has spawned new forms of interactivity in the form of social media, email, blogs, online forums, chat rooms and websites. This growth has been fuelled by cheaper and smaller mobile devices leading to increased opportunities to share information, preferences, opinions and ideas-information diffusion.

Opinions, ideas and thoughts are contagious. Going viral is one of the buzzwords used to describe their contagiousness and speed of spread on the Internet-often with no regard to their veracity and without much critical examination [17]. "Participation in opinion-based groups produces psychological transformations that impact on behavior, beliefs, and emotions" [18]. Information diffusion has been compared to the spread of epidemics and has been modelled using an SIR epidemic model [19-21]. The SIR model is used "to represent the process of topic diffusion through continuous discussions about a topic on Web forums" [21]. It is spread when an initiating author posts a thread to start a discussion which may then infect others with his ideas. Other users who are interested in the topic will read and post comments on the thread and will post other threads, thereby infecting others with their posts [20]. In the SIR model, 'S' represents possible users, 'I' represents interested users and ' $R$ ' represents those who stop participating in discussions and lose the power to influence others.

Fittingly enough, the transmission of viruses and other malicious objects such as worms and trojan horses in computer network via electronic mail and the use of secondary devices has been compared with the spread of an infectious disease. Modifications of SIR and SEIR infectious disease models have been used to model the spread of these objects, where for instance susceptible individuals correspond to susceptible computers, i.e. virus-free computers having no 
immunity, latent individuals correspond to infected computers in which all viruses are in latency, infected individuals correspond to infected computers with at least one virus and recovered individuals correspond to recovered computers, i.e virus-free computers having immunity [22-25]. Other models include an epidemic model which combines both vaccinations and quarantine methods, the SEIQV model [26], while a SEIQRS model has been developed for the transmission of malicious objects in computer network [24].

\section{Radical behavior, fanaticism, crime and violence}

The media inundates us with news of terrorist groups, their radical behaviour and its usually violent aftermath. Models have been used to study the spread in ideology in a region where some groups want to attain independence through violence [27], as well as to examine the transmission dynamics of fanatic behaviors [28]. Camacho [29] extended the work of [28] to include interaction between two violent groupswith and without interaction between these groups. The importance of Social Media as a tool for spreading extreme opinions or ideologies was recognised by Woo et al. [20] who used a SIR model to model violent topic diffusion in a Jihadi forum.

Violence may be treated as a socially infectious disease [30], with a public health approach to the control of infectious disease, used in violence prevention. Campbell and Ormerod [31] and Ormerod et al. [32] applied an infectious disease model to violent crime and burglary in the United Kingdom.

Other forms of violent behavior also lend themselves to these types of models. Since association with delinquent peers is one of the strongest risk factors for gang membership [33], gang membership can be treated as an infection that multiplies due to interaction or peer contagion whereby 'infected' youth convert vulnerable or susceptible youth $[34,35]$ to a life in the gang. Criminal behaviour was also treated as an infection with regards to property crime- spread from criminals to non-criminals in a population divided into classes by employment and criminal status [36].

\section{Social addictions, eating disorders and the growth of church and political parties}

In 2013, it is estimated that a total of 246 million people, or 1 out of 20 people between the ages of 15 and 64 years used an illicit drug [37]. The harmful use of alcohol ranks among the top five risk factors for disease, disability and death throughout the world [38]. The role of peer influence in encouraging or discouraging these behaviors is important. Susceptible members of the population acquire the habits (and become infected or addicts) via effective 'contacts' with drinkers, smokers or drug addicts. Treatment may be included in these models via a treatment class and the recovered class. Addictive behaviors modelled include alcoholism [39-44], smoking [45] and the use of ecstasy, crystal meth and heroin [46-49].

Researchers have noted the similarity between addictions and eating disorders [2]. Therefore, it is not surprising that infectious disease models have also found a home in the modelling of eating disorders [50] and obesity [51].

Karl Marx famously referred to religion as the opiate of the masses and with this in mind, the growth of religion (quantified by numbers of the faithful or church members) was included in this category-though this process may have just as easily fit in any of the other categories. A SIR model was used to model the growth of the population of a church $[52,53]$. It is assumed that the dynamics of the growing church resembles that of the spread of a disease, with enthusiasts analogous to those infected with the disease. In this model, ' $S$ ' represents the number of susceptibles, the unbelievers, with whom the church members have contact. 'I' represents enthusiasts, or 'infected' believers, within the church who are active in spreading the faith and ' $R$ ' represents the removed church members who have a negligible role in garnering converts.

The idea behind these models describing the growth of a church is similar to that used to model the growth of political parties. Romero et al. [54] assumed that third parties (political parties operating along with two major parties in a bipartisan system over a limited period of time) grow in a similar manner to epidemics in a population with the party faithful (activists) playing an extensive role in the growth of the party. Jeffs et al. [55] in what was termed an "Activist Model of Political Party Growth" used a SIR model to examine the role of activists in the growth of a political party. Here 'S' represents those who do not belong to the political party (susceptibles), the party faithful (the members) are divided into recruiting activists 'I' who are "infectious" and recruit susceptibles by word of mouth, non-recruiting activists ' $\mathrm{A}$ ' and inactive members ' $\mathrm{M}$ ', both of whom play no part in the recruitment process. The model was applied to membership of British political parties and found to reproduce observed data trends.

\section{Conclusion}

"Mathematical epidemiology seems to have grown exponentially starting in the middle of the twentith century" [6]. This has led to a variety of models of infectious diseases. However, as far as we can determine, the widespread application of compartmental models to a variety of social and behavioral phenomena is of a fairly recent nature.

The importance of these models lies in their uses to generate estimates when data is sparse, verify hypotheses and to 
perform 'virtual' experiments to evaluate the efficacy of different prevention strategies and can complement traditional approaches to research Castiglione [56].

We must note however, that although the fundamental dynamics of contact and spread of social contagion and infectious diseases may be comparable, some characteristics of the two dynamics are fundamentally different. Accordingly, problems arise in estimating key parameters like contact rates since this may be dependent on behavior of human beings which may be difficult to quantify and observe.

The use of social media has been implicated in the 2011 UK riots and the Arab Spring [18,57]. Given the current political climate around the world with the rise of extreme ideologies in many parts of the globe and the large number of people suffering from addictions and victims of crime, models that can provide insight into how such ideologies, opinions and addictions spread in a society and how they can be reduced are of great relevance and interest.

\section{Compliance with ethical standards}

Conflict of interest The authors declare that they have no conflict of interest (financial or non-financial) associated with the preparation or submission of this manuscript.

Human and animals rights This review article does not contain any studies with human participants or animals performed by any of the authors.

Ethical approvals No form of ethical approvals were necessary, and no informed consent was required by either author. All accepted principles of ethical and professional conduct have been strictly observed.

\section{References}

1. Gladwell M (2000) The tipping point: how little things can make a big difference. Little Brown and Company, Boston

2. Lesieur H, Blume S (1993) Pathological gambling, eating disorders, and the psychoactive substance use disorders. J Addict Dis 12(3):89-102

3. Brauer F, Castillo-Chavez C (2001) Mathematical models in population biology and epidemiology. In: Texts in applied mathematics, vol 40. Springer, New York

4. Lucey DR, Gostin LO (2016) The emerging zika pandemic: enhancing preparedness. J Am Med Assoc 315(9):865-866

5. Brauer F, Van Den Driessche P, Wu J, Allen LJS (2008) Mathematical epidemiology. In: Mathematical biosciences subseries. Springer

6. Hethcote HW (2000) The mathematics of infectious diseases. SIAM Rev 42(4):599-653

7. Nishiura H, Kinoshita R, Mizumoto K, Yasuda Y, Nah K (2016) Transmission potential of Zika virus infection in the South Pacific. Int J Infect Dis 45:95-9. http://www.sciencedirect.com/science/ article/pii/S1201971216000370

8. Kucharski AJ, Funk S, Eggo RM, Mallet H, Edmunds WJ, Nilles EJ (2016) Transmission dynamics of zika virus in island populations: a modelling analysis of the 2013-14 French Polynesia outbreak. PLoS Negl Trop Dis

9. Bewick S, Fagan WF, Calabrese JM, Agusto F (2016) Zika virus: endemic versus epidemic dynamics and implications for disease spread in the Americas. bioRxiv
10. Rodgers JL, Rowe DC, Buster M (1998) Social contagion, adolescent sexual behavior, and pregnancy: a nonlinear dynamic emosa mode. Dev Psychol 34(5):1096-1113

11. Brown C (1995) Serpents in the sand: essays on the nonlinear nature of politics and human destiny. University of Michigan Press, Ann Arbor

12. Goffman W, Newhill VA (1964) Generalization of epidemic theory: an application to the transmission of ideas. Nature 204:225-228

13. Goffman W (1966) Mathematical approach to the spread of scientific ideas - the history of mast cell research. Nature 212:449-452. http://www.nature.com/nature/journal/v212/n5061/abs/212449a0. html

14. Bettencourt LMA, Cintron-Arias A, Kaiser DI, Castillo-Chavez C (2006) The power of a good idea: quantitative modeling of the spread of ideas from epidemiological models. Phys A 364:513-536

15. Bettencourt L, Kaiser D, Kaur J, Castillo-Chavez C, Wojick D (2008) Population modeling of the emergence and development of scientific fields. Scientometrics 5(3):495-518

16. Jin F, Dougherty E, Saraf P, Ramakrishnan N (2013) Epidemiological modeling of news and rumors on Twitter. In: Proceedings of the 7th workshop on social network mining and analysis, (article number 8), ACM Digital Library

17. Graham L (2003) 'Of course it's true; I saw it on the internet!': critical thinking in the internet era. Commun ACM 46(5):71-75

18. McGarty C, Thomas EF, Lala G, Smith LGE, Bliuc A (2013) New technologies, new identities, and the growth of mass opposition in the Arab Spring. Polit Psychol 35(6):725-740

19. Kubo M, Naruse K, Sato H, Matubara T (2007) The possibility of an epidemic meme analogy for web community population analysis. Springer, Berlin, pp 1073-1080

20. Woo J, Son J, Chen H (2011) An SIR model for violent topic diffusion in social media. In: ISI, IEEE, pp 15-19

21. Woo J, Chen H (2016) Epidemic model for information diffusion in web forums: experiments in marketing exchange and political dialog. SpringerPlus 5:66

22. Gan C, Yang X, Liu W, Zhu Q, Zhang X (2012) Propagation of computer virus under human intervention: a dynamical model. Discr Dyn Nat Soc. Article ID 106950

23. Mishra BK, Saini DK (2007) SEIRS epidemic model with delay for transmission of malicious objects in computer network. Appl Math Comput 188(2):1476-1482

24. Mishra BK, Jhab N (2010) SEIRS model for the transmission of malicious objects in computer network. Appl Math Model 34(3):710-715

25. Piqueira JRC, Navarro BF, Monteiro LHA (2005) Epidemiological models applied to viruses in computer networks. J Comput Sci $1(1): 31-34$

26. Wang F, Zhang Y, Wang C, Ma J, Moon SJ (2010) Stability analysis of a SEIQV epidemic model for rapid spreading worms. Comput Secur 29(4):410-418

27. Santonja FJ, Tarazona AC, Villanueva RJ (2008) A mathematical model of the pressure of an extreme ideology on a society. Comput Math Appl 56(3):836-846

28. Castillo-Chavez C, Song B (2003) Models for the transmission dynamics of fanatic behaviors. In: Banks HT, Castillo-Chávez C (eds) Bioterrorism: mathematical modeling applications in homeland security, SIAM frontiers in applied mathematics, vol 28. SIAM, Philadelphia, pp 155-172

29. Camacho ET (2013) The development and interaction of terrorist and fanatic groups. Commun Nonlinear Sci Numer Simul 18(11):3086-3097. https://asu.pure.elsevier.com/en/publications/ the-development-and-interaction-of-terrorist-and-fanatic-groups

30. Bingenheimer JB, Brennan RT, Earls FJ (2005) Firearm violence exposure and serious violent behavior. Science 308:1323-1326

31. Campbell M, Ormerod P (1997) Social interaction and the dynamics of crime. Technical report. Volterra Consulting Ltd 
32. Ormerod P, Mounfield C, Smith L (2001) Non-linear modelling of burglary and violent crime in the UK. In: Lewis C (ed) Modelling crime and offending: recent developments in England and Wales, vol 80. Research, Development and Statistics Directorate, London

33. Katz CM, Fox AM (2010) Risk and protective factors associated with gang-involved youth in Trinidad and Tobago. Pan Am J Public Health 27(3): 187-202

34. Sooknanan J, Bhatt BS, Comissiong DMG (2012) Life and death in a gang - a mathematical model of gang membership. J Math Res 4(4):10-27. http://www.ccsenet.org/journal/index.php/ jmr/article/view/17782

35. Sooknanan J, Bhatt BS, Comissiong DMG (2013) Catching a gang - a mathematical model of the spread of gangs in a population treated as an infectious disease. Int J Pure Appl Math 83(1):25-43. http://www.ijpam.eu/contents/2013-83-1/4/4.pdf

36. Mushayabasa S (2015). Modeling optimal intervention strategies for property crime. Int J Dyn Control 1-10

37. The United Nations Office on Drugs and Crime (2015) World drug report 2015. Technical report, United Nations

38. World Health Organization (2014) Global status report on alcohol and health 2014. World Health Organization, Technical report

39. Lee S, Jung E, Castillo-Chavez C (2010) Optimal control intervention strategies in low- and high-risk problem drinking populations. Soc Econ Plan Sci 44(4):258-265

40. Mulone G, Straughan B (2012) Modeling binge drinking. Int J Biomath 05(01):1250005

41. Mushayabasa S (2015) The role of optimal intervention strategies on controlling excessive alcohol drinking and its adverse health effects. J Appl Math. Article ID. 238784

42. Sharma S, Samanta GP (2015) Analysis of a drinking epidemic model. Int J Dyn Control 3(3):288-305

43. Sanchez F, Wang X, Castillo-Chavez C, Gorman DM, Gruenewald PJ (2007) Drinking as an epidemic: a simple mathematical model with recovery and relapse. In: Therapist's guide to evidence based relapse prevention, Elsevier Inc., pp 353-368. doi:10.1016/ B978-012369429-4/50046-X

44. Wang X, Huo H, Kong Q, Shi W (2014) Optimal control strategies in an alcoholism model. Abst Appl Anal. Article ID 954069

45. Sharomi O, Gumel AB (2008) Curtailing smoking dynamics: a mathematical modeling approach. Appl Math Comput 195(2):475499
46. Nyabadza F, Musekwa SD (2010) From heroin epidemics to methamphetamine epidemics: modelling substance abuse in a South African province. Math Biosci 225(2):132-140

47. Nyabadza F, Njagarah JBH, Smith RJ (2012) Modelling the dynamics of crystal meth ('tik') abuse in the presence of drug-supply chains in South Africa. Bull Math Biol 75(1):24-48

48. Song B, Castillo-Garsow M, Rios-Soto KR, Mejran M, Henso L, Castillo-Chavez C (2006) Raves, clubs, and ecstasy: the impact of peer pressure. Math Biosci Eng 3(1):249-266

49. White E, Comiskey C (2007) Heroin epidemics, treatment and ODE modelling. Math Biosci 208:312-324

50. Gonzalez B, Huerta-Sanchez E, Ortiz-Nieves A, Vazquez-Alvarez T, Kribs-Zaleta C (2003) Am I too fat? Bulimia as an epidemic. J Math Psychol 47:515-526

51. Santonja FJ, Morales A, Villanueva RJ, Cortes JC (2012) Analysing the effect of public health campaigns on reducing excess weight: a modelling approach for the Spanish autonomous region of the community of Valencia. Eval Progr Plan 35(1):34-39

52. Hayward J (1999) Mathematical modeling of church growth. J Math Sociol 23(4):255-292

53. Hayward J (2005) A general model of church growth and decline. J Math Sociol 29(3):177-207. http://www.churchmodel.org.uk/ Hayward2005.pdf

54. Romero DM, Kribs-Zaleta CM, Mubayi A, Orbe C (2011) An epidemiological approach to the spread of political third parties. Discr Contin Dyn Syst Ser B 15(3):707-738

55. Jeffs RA, Hayward J, Roach PA, Wyburn J (2016) Activist model of political party growth. Phys A Stat Mech Appl 442:359-372

56. Castiglione F (2006) Agent based modeling. Scholarpedia 1(10): 1562

57. Baker SA (2012) From the criminal crowd to the mediated crowd: the impact of social media on the 2011 English riots. Safer Commun 11(1):40-49

58. Lindzey G, Aronson E (1985) The handbook of social psychology: group psychology and phenomena of interaction. In: The handbook of social psychology, 3rd edn. Addison-Wesley Publishing Company 